\title{
M. A. Pavlidis and C. C. Mylonas (eds): Sparidae: biology and aquaculture of gilthead sea bream and other species
}

\author{
Wiley-Blackwell, Chichester, 2011, XVII + 390 pp, $£ 140$ \\ (Hardback), ISBN: 978-1-4051-9772-4
}

\section{Malcolm Jobling}

Received: 31 May 2011/Accepted: 31 May 2011/Published online: 15 June 2011

(C) The Author(s) 2011. This article is published with open access at Springerlink.com

Sparidae is a multiauthor volume compiled and edited by Michail Pavlidis and Constantinos Mylonas. The names of most of the contributors will be familiar to those who have kept abreast of developments within Mediterranean aquaculture, and sea bream, research. The main focus of the book is on the culture of porgies and sea breams, with general biology tending to take a back seat. Nonetheless, there are a couple of chapters that do not have much intrusion from aquaculture and quite a lot of general biological information has been woven into several of the other chapters. Throughout the book, there is an emphasis on the culture of gilthead sea bream, Sparus aurata, which, along with the European sea bass, Dicentrarchus labrax, currently forms the mainstay of the Mediterranean mariculture industry.

The book opens with an overview of fisheries and aquaculture statistics for the most economically important sparid fishes and includes a cursory look at the methods used to produce the main farmed species. There is also a brief summary of the systematics and general biology of this family of fishes. The authors try to cover so much ground that the presentation has a tendency to be rather staccato, and at times, the text does not gel particularly well. This means that the book does not get off to an ideal start. In addition, most of the themes covered in Chapter 1 are taken up and expanded upon in later chapters. For example, taxonomy, systematics, and general biology that are compressed into short paragraphs in Chapter 1 are also given an entire chapter (Chapter 2); there are some differences, mostly minor, in the factual information presented in these two chapters. I would have preferred the book to start with the overview of sparid taxonomy, systematics, and general biology and for the book to close with the summary chapter that opens it.

Given that the book deals with a single family of fishes and mostly concentrates on the farming of single member within the family, the majority of chapters give in-depth coverage of their topics, providing a lot of detail, and include fairly comprehensive and up-todate reference lists. As to be expected in a book devoted predominantly to aquaculture, there are chapters that cover brood-stock management and reproduction, early development and larval production, and feeding and nutrition. There are also chapters that provide

M. Jobling $(\bowtie)$

University of Troms $\emptyset, 9037$ Troms $\emptyset$, Norway

e-mail: malcolm.jobling@uit.no 
information about production systems, diseases and health management, stress physiology and welfare, and the contribution that modern technologies can make to the genetic improvement of farmed stocks. Pigmentation problems and production deformities that may be encountered when farming sparid fishes, with emphasis on the culture of gilthead sea bream, are also covered.

A few of the chapters bear telltale signs of having been written by authors who do not have English as their first language. There are also some aspects of structure and organization that could have been improved upon. For example, several chapters end rather abruptly without any summary closing statements. In addition, there are a few oddities in the presentation. For example, each of the species covered in Chapter 1 is illustrated using both a sketch and a black-and-white photograph, and colour versions of the photographs can be found in the Plates section of the book. The colour photographs for all chapters have been collected together in the Plates section, and black-and-white versions of the photographs are presented in each of the chapters, but not all of the black-and-white photographs that adorn the main text have full-colour alternatives. This leads to some incongruity because the reader is not always sure whether or not there is both a black-and-white and a colour photograph, and an additional problem is that the black-and-white photographs are not always very illustrative of the point being made. Particularly, obvious cases are Figure 9.1 (Plate 9.1) and Figure 9.2 (Plate 9.2) that show the main skin colour patterns in fish and pigmentation patterns of Sparidae, respectively. The end result of the type of presentation chosen was that I often had to flip to-and-fro through the book to get the benefit of seeing the colour illustrations. This was a bit irritating and distracting at times, especially as it was not always easy to locate the plates quickly; somewhat strangely the Plates section has been placed mid-way through Chapter 1 .

Other quibbles that relate to structure and presentation include the following. Many of the tables are large and unwieldy, making it difficult to extract information easily and effectively, there is sometimes lack of concordance in the information given in different chapters, and there are also a few factual and printing errors. Figure 11.1 can be used to exemplify the latter; in this figure, the spellings of Protacanthopterygii and Oncorhynchus are incorrect, Salmo salar is presented as Salmon salar, Oryzia should be Oryzias, the Ostariophysi (carps, freshwater catfishes, etc.) have been placed within the Euteleostei (rather than the currently accepted Otocephali), and the spelling of Euteleostei given in the figure legend differs from the spelling used in the figure itself.

Although Sparidae gives some coverage of biology and cultivation of several porgies and sea breams, it concentrates on the aquaculture of gilthead sea bream; it is useful to have so much pertinent information about this commercially important, warm-water marine fish gathered together in a single book. The book is most likely to be read by aquaculture scientists and commercial producers in Mediterranean countries, but it also has something to offer all those with interests in the biology and cultivation of warm-water, marine fishes. The book can also act as a source of reference for aquaculture researchers and students in other parts of the world.

Open Access This article is distributed under the terms of the Creative Commons Attribution Noncommercial License which permits any noncommercial use, distribution, and reproduction in any medium, provided the original author(s) and source are credited. 